Revta brasil. Bot., São Paulo,V.24, n.4 (suplemento), p.561-566, dez. 2001

\title{
Crescimento inicial de Piptadenia gonoacantha (Leguminosae, Mimosoideae) sob inundação em diferentes níveis de luminosidade.
}

\author{
JOICE NUNES FERREIRA ${ }^{1,3}$, JOSÉ FELIPE RIBEIRO ${ }^{2,3}$ e CARLOS EDUARDO LAZARINI DA \\ FONSECA $^{2}$
}

(recebido: 06 de setembro de 2000; aceito: 27 de junho de 2001)

\begin{abstract}
Initial growth of Piptadenia gonoacantha (Leguminosae, Mimosoideae) under flooding and different light conditions). This study focus on ecological aspects of flooding on five month old seedlings of Piptadenia gonoacantha, a Gallery forest species. Seedling growth rates were evaluated on three levels of sun light $(100 \%, 70 \%$ and $40 \%)$ and two soil moisture conditions (field capacity and flooded). Flooding reduced aerial and root growth. There was no interaction between light intensity and flooding, except for foliar dry matter (60 days) and top/root ratio (20 days). Full sun light seedlings under flooding had $67 \%$ lower foliar dry matter production than shaded ones, after 60 days. Flooded seedlings in all three light levels, had hypertrophic lenticels on submerged stems, after 20 days. In additon, flooding induced root decomposition but no adventicious roots were observed. After 60 days of flooding, seedlings of $P$. gonoacantha presented $100 \%$ survival and no significant injury on the top portion.
\end{abstract}

RESUMO - (Crescimento inicial de Piptadenia gonoacantha (Leguminosae, Mimosoideae) sob inundação em diferentes níveis de luminosidade). Este estudo aborda aspectos ecológicos da inundação em plântulas de Piptadenia gonoacantha, uma espécie ocorrente em Matas de Galeria. O crescimento de plântulas com cinco meses de idade foi avaliado em duas condições de solo (capacidade de campo e inundado) combinados com três níveis de luz solar $(100 \%, 70 \%$ e $40 \%)$. A inundação reduziu o crescimento aéreo e radicial das plântulas. Não houve interação entre luz e inundação, exceto para massa seca foliar aos 60 dias e razão parte aérea/raiz aos 20 dias. Plântulas inundadas a pleno sol apresentaram massa seca foliar aos 60 dias cerca de $67 \%$ menor que aquelas inundadas sombreadas. A razão parte aérea/raiz de plântulas inundadas foi significativamente maior aos 60 dias. Plântulas inundadas produziram lenticelas hipertrofiadas na base do caule, a partir dos 20 dias, em todos os níveis de luz. Além disso, a inundação induziu a decomposição das raízes e raízes adventícias não foram observadas. Após 60 dias de inundação, plântulas de $P$. gonoacantha apresentaram $100 \%$ de sobrevivência sem sintomas significantes de injúria na parte aérea.

Key words - Gallery Forest, flooding tolerance, irradiance, Piptadenia gonoacantha

\section{Introdução}

As Matas de Galeria, formações florestais associadas a pequenos cursos de água dos planaltos do Brasil Central, são ambientes sujeitos a inundações periódicas. Nestas matas, o lençol freático pode ficar próximo ou sobre a superfície na maior parte dos trechos, durante o ano todo, inclusive na estação seca (Ribeiro \& Walter 1998).

1. Universidade de Brasília, Instituto de Biologia, ICC Norte, Asa Norte, Caixa Postal 04631, 70000-000 Brasília, DF, Brasil.

2. Embrapa Cerrados, BR 020, Rod. Brasília-Fortaleza, km 18, Caixa Postal 08223, 73301-970, Brasília, DF, Brasil.

3. Autor para correspondência: felipe@cpac.embrapa.br
É verificada uma diferença na composição florística entre sítios inundáveis e não inundáveis das Matas de Galeria (Ribeiro \& Walter 1998), refletindo o papel da inundação no processo seletivo que determina a distribuição das espécies nestes ambientes (Joly 1986).

A inundação do solo desencadeia uma série de processos químicos, físicos e biológicos que comprometem a sua capacidade de sustentar o crescimento das plantas (Ponnamperuma 1984). Vários fatores influenciam os efeitos da inundação nas plantas, dentre eles, a recorrência do estresse, a altura da lâmina de água que cobre o solo (Harms et al. 1980), a periodicidade, duração e intensidade da inundação, a velocidade (água corrente ou parada) a qualidade da água e a taxa de sedimentação (Kozlowski 1997).

Björkam \& Powles (1984) fazem considerações acerca da interação entre a 
luminosidade e o estado de água das plantas. Como é verificada uma variedade de ambientes de luz nas matas de galeria, as respostas das plantas à inundação provavelmente interagem com a luminosidade.

Piptadenia gonoacantha é uma espécie que ocorre em matas de galeria do Distrito Federal, sendo, em relação ao estádio sucessional, classificada como pioneira a secundária inicial (Carvalho 1994).

O objetivo deste trabalho foi avaliar o grau de tolerância à inundação, em diferentes níveis de luz, de plântulas de Piptadenia gonoacantha. Com esta informação, espera-se contribuir para a compreensão da distribuição espacial dessa espécie nas matas de galeria do Brasil Central e, assim, subsidiar planos de conservação destas fisionomias que se encontram bastante ameaçadas.

\section{Material e métodos}

Produção de plântulas - As plântulas foram obtidas a partir da germinação de sementes coletadas de seis indivíduos, em setembro de 1998, no município de Formosa, Goiás. Com 15 dias de idade, foram transferidas para tubos de plástico $(19,5$ x $5,0 \mathrm{~cm})$ contendo latossolo e esterco bovino curtido $(2: 1)$. Continuaram o desenvolvimento em viveiro, com duas irrigações diárias, até atingir cinco meses de idade, quando foi dado início ao experimento. A duração do experimento foi de 60 dias. Não foram aplicados nutrientes ao solo no decorrer do ensaio.

Desenho experimental - $\mathrm{O}$ experimento, composto de seis tratamentos, combinou duas condições de solo (capacidade de campo e inundado) com três níveis de luminosidade (100\%, $70 \%$ e $40 \%$ ). Telas de "nylon" (sombrite) foram usadas para produzir os níveis de luminosidade selecionados. Foram realizadas três avaliações, incluindo 20 plantas por avaliação. Cada planta foi considerada uma repetição. $\mathrm{O}$ intervalo de amostragem foi de 20 dias.

As plântulas dos tratamentos inundados foram distribuídas, de modo casualizado, em tanques de concreto com água corrente, ficando submersas cerca de $4 \mathrm{~cm}$ acima do nível do substrato. Nos tratamentos denominados de capacidade de campo, as plântulas foram mantidas em viveiro, com duas irrigações diárias.

Análise de Crescimento - No dia anterior ao início do experimento, foram tomadas medidas do número de folhas e do comprimento do caule (do nível do substrato até o ápice do meristema terminal). Análise de crescimento foi feita para 10 plantas no início do experimento (testemunha) e para 20 plantas a cada 20 dias. Nesta análise foram incluídos: número de folhas, comprimento do caule e raiz, massa seca de folhas (limbo e pecíolo), caule e raiz, separadamente. Para comprimento de raiz, mediu-se a extensão da raiz principal. A massa seca de folhas, caules e raízes foi determinada após secagem em estufa a $60{ }^{\circ} \mathrm{C}$ por 72 horas.

Avaliação de respostas morfológicas - Ao final de cada período, era feita avaliação visual, investigando o surgimento de alterações morfológicas nas plântulas. Como foram observadas lenticelas na base do caule de plantas inundadas desde os 20 dias, retirou-se, no final do experimento, segmentos dessa região em três indivíduos de cada tratamento, para análise microscópica. Os segmentos, com cerca de $2 \mathrm{~cm}$, foram desidratados em série alcoólica, incluídos em parafina, cortados em micrótomo de deslize e corados com safranina e "fast green".

Análise estatística - Foi feita análise de variância (sem transformação dos dados) após testar a homogeneidade da variância. Considerou-se a estrutura do tratamento como um fatorial (duas condições de solo e três níveis de luz) em delineamento experimental inteiramente casualizado com 20 repetições. Comparou-se a diferença entre as médias através do teste de Tukey nos níveis de $1 \%$ e 5\% de probabilidade.

\section{Resultados}

Plântulas de $P$. gonoacantha mostraram rápido crescimento sob capacidade de campo, enquanto a inundação reduziu o crescimento aéreo e radicial desta espécie (figura 1).

Houve diferença significativa, pelo menos em um período, entre os tratamentos de inundação para todos os parâmetros estudados, exceto comprimento da raiz (tabela 1). Para a maioria, as diferenças foram detectadas desde o primeiro período de avaliação (20 dias) e foram mantidas até o último (60 dias).

A inundação reduziu em $45 \%$ o número de folhas (tabela 1). Aos 20 e 40 dias, a massa seca das folhas foi cerca de 50\% menor sob inundação (tabela 1). A inundação também reduziu cerca de $70 \%$ da massa seca do caule (tabela 1). Apesar de não ter sido detectada diferença significativa para o comprimento da raiz principal, a massa seca radicial foi reduzida em aproximadamente $56 \%$ pela inundação.

Diferenças na razão parte aérea/raiz só foram observadas no final do experimento, com aumento de cerca de $44 \%$ para as plântulas inundadas.

Variações na luminosidade não determinaram diferenças significativas na maioria dos parâmetros avaliados. Observou-se diferenças significativas entre os níveis de luz apenas para razão parte aérea/ raiz aos 60 dias e número de folhas em todos os períodos. Apesar de plantas a pleno sol terem reduzido cerca de $22 \%$ do número de folhas comparadas às plantas a $40 \%$ de luz, diferenças não foram observadas para a massa seca foliar (tabela 

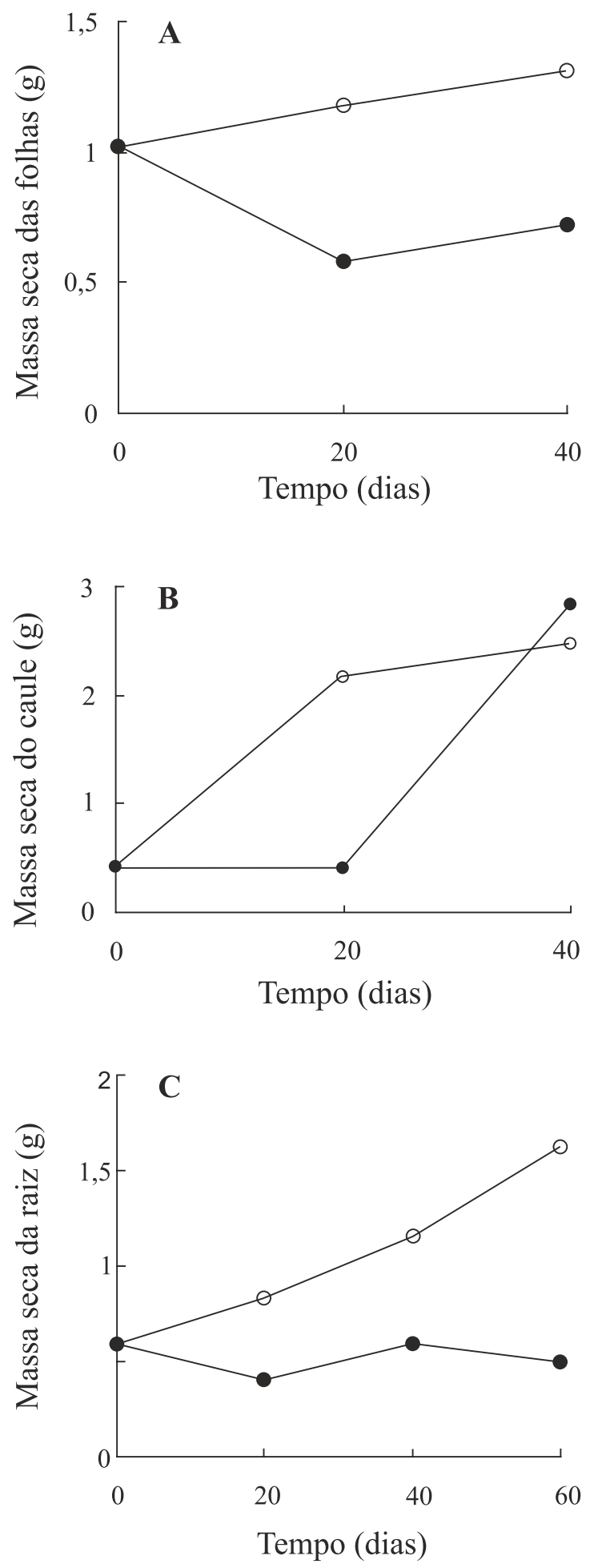

Figura 1. Massa seca das folhas (A), caule (B) e raiz (C) de plântulas de Piptadenia gonoacantha crescendo por 60 dias sob capacidade de campo (o) e inundação $(\bullet)$.
1). Não houve interação entre luminosidade e inundação para a maioria dos parâmetros de crescimento avaliados, exceto massa seca das folhas aos 60 dias e razão parte aérea/raiz aos 20 dias (tabela 2).

Verificou-se, para massa seca foliar, que apenas as plantas inundadas responderam diferentemente aos níveis de luz. Plântulas inundadas a pleno sol apresentaram massa seca foliar, aos 60 dias, cerca de $70 \%$ menor que das plântulas inundadas e sombreadas (tabela 2).

Desde o primeiro período de avaliação, verificou-se, nas plântulas inundadas, protrusão de numerosas lenticelas de cor esbranquiçada na região submersa do caule, logo acima da superfície do substrato. Estas estruturas ocorreram em todos os níveis de luminosidade. Os cortes histológicos mostraram que as lenticelas eram hipertrofiadas e não continham camadas fechadas.

Foram verificados sinais de decomposição nas raízes de plantas inundadas sem evidência de formação de raízes adventícias ou sintomas de injúria da parte aérea, como necrose e murchamento das folhas. Além disso, foi observada, em plantas a pleno sol, queda foliar desde os 20 dias.

\section{Discussão}

Plântulas de $P$. gonoacantha tiveram o crescimento bastante reduzido sob inundação, mas foram capazes de sobreviver a esse estresse sem apresentar, na parte aérea, sintomas característicos de plantas intolerantes, como necrose e senescência foliar.

Ao contrário da inundação, o efeito da luminosidade não foi evidente sobre o crescimento das plântulas. Em capacidade de campo, $P$. gonoacantha mostrou-se tolerante a todos os ambientes de luz, não apresentando diferenças significativas no crescimento, para a maioria dos parâmetros, entre os três níveis estudados. Embora não se tenha informação sobre os pontos de compensação e saturação desta espécie, os resultados obtidos levam a crer que todas as intensidades luminosas utilizadas tenham sido saturantes para a sua fotossíntese. Boardman (1977) discute que as características fotossintéticas são induzidas pela intensidade luminosa sob a qual a planta cresce, de modo que folhas de espécies de sol crescendo sob baixa intensidade luminosa 
Tabela 1. Valores médios das medidas de crescimento de Piptadenia gonoacantha que não apresentaram interação entre duas condições do solo (cc capacidade de campo e in inundado) e três níveis de luz (100\%, 70\% e 40\%). (NF) número de folhas, (MSF) massa seca das folhas, (CC) comprimento do caule, (MSC) massa seca do caule, (CR) comprimento da raiz, (MSR) massa seca da raiz e (PAPR) razão parte aérea/raiz. Valores da mesma linha seguidos da mesma letra não diferem significativamente em $\mathrm{P}<0,05$.

\begin{tabular}{|c|c|c|c|c|c|c|c|c|}
\hline \multirow{3}{*}{$\begin{array}{l}\text { MEDIDAS DE } \\
\text { CRESCIMENTO }\end{array}$} & \multirow{3}{*}{$\begin{array}{l}\text { TEMPO } \\
\text { (DIAS) }\end{array}$} & \multicolumn{7}{|c|}{ FATORES } \\
\hline & & \multicolumn{3}{|c|}{ CONDIÇÃO SOLO } & \multicolumn{4}{|c|}{ LUZ (\%) } \\
\hline & & $\mathrm{cc}$ & in & Média & 100 & 70 & 40 & Média \\
\hline \multirow[t]{3}{*}{ NF } & 20 & 12,55 & 7,73 & $10,14^{* * *}$ & $9,42 \mathrm{a}$ & $9,72 \mathrm{a}$ & $11,27 \mathrm{~b}$ & $10,13^{*}$ \\
\hline & 40 & 11,10 & 6,03 & $8,56^{* * *}$ & $7,32 \mathrm{a}$ & $8,75 \mathrm{~b}$ & $9,62 \mathrm{~b}$ & $8,56 * *$ \\
\hline & 60 & 8,68 & 4,32 & $6,50 * * *$ & $5,47 \mathrm{a}$ & $6,50 \mathrm{ab}$ & $7,52 \mathrm{~b}$ & $6,50^{*}$ \\
\hline \multirow[t]{2}{*}{ MSF } & 20 & 1,18 & 0,58 & $0,88^{* * *}$ & 0,85 & 0,83 & 0,95 & $0,88 \mathrm{~ns}$ \\
\hline & 40 & 1,31 & 0,72 & $1,01^{* * *}$ & 0,94 & 1,05 & 1,05 & $1,01 \mathrm{~ns}$ \\
\hline \multirow[t]{3}{*}{$\mathrm{CC}$} & 20 & 27,55 & 20,34 & $23,94 * * *$ & 22,45 & 23,69 & 25,69 & $23,94 \mathrm{~ns}$ \\
\hline & 40 & 28,67 & 22,60 & $25,63 * * *$ & 25,17 & 26,21 & 25,53 & $25,64 \mathrm{~ns}$ \\
\hline & 60 & 29,48 & 22,26 & $25,87 * * *$ & 23,76 & 26,57 & 27,28 & $25,87 \mathrm{~ns}$ \\
\hline \multirow[t]{3}{*}{ MSC } & 20 & 2,18 & 0,41 & $1,29 * *$ & 1,84 & 0,73 & 1,32 & $1,30 \mathrm{~ns}$ \\
\hline & 40 & 2,48 & 2,85 & $2,66 \mathrm{~ns}$ & 2,06 & 2,23 & 3,71 & $2,70 \mathrm{~ns}$ \\
\hline & 60 & 5,69 & 2,31 & $4,00 * *$ & 3,39 & 3,98 & 4,63 & $4,00 \mathrm{~ns}$ \\
\hline \multirow[t]{3}{*}{$\mathrm{CR}$} & 20 & 22,56 & 22,68 & $22,62 \mathrm{~ns}$ & 22,33 & 22,43 & 23,10 & $22,62 \mathrm{~ns}$ \\
\hline & 40 & 23,49 & 24,54 & 24,01 & 22,93 & 24,97 & 24,15 & $24,02 \mathrm{~ns}$ \\
\hline & 60 & 24,75 & 24,47 & $24,61 \mathrm{~ns}$ & 23,73 & 25,24 & 24,86 & $24,61 \mathrm{~ns}$ \\
\hline \multirow[t]{3}{*}{ MSR } & 20 & 0,83 & 0,41 & $0,62^{* * *}$ & 0,65 & 0,58 & 0,62 & $0,62 \mathrm{~ns}$ \\
\hline & 40 & 1,16 & 0,59 & $0,87^{* * *}$ & 0,10 & 0,81 & 0,81 & $0,57 \mathrm{~ns}$ \\
\hline & 60 & 1,62 & 0,50 & $1,06^{* * *}$ & 1,14 & 0,99 & 1,05 & $1,06 \mathrm{~ns}$ \\
\hline \multirow[t]{2}{*}{ PAPR } & 40 & 2,14 & 2,68 & $2,41 \mathrm{~ns}$ & 2,06 & 2,34 & 2,84 & $2,41 \mathrm{~ns}$ \\
\hline & 60 & 1,60 & 2,86 & $2,23 * * *$ & $1,68 \mathrm{a}$ & $2,60 \mathrm{~b}$ & $2,41 \mathrm{ab}$ & $2,23^{*}$ \\
\hline
\end{tabular}

ns = não significativo, ${ }^{*} \mathrm{p}<0,05,{ }^{* *} \mathrm{p}<0,01,{ }^{* * *} \mathrm{p}<0,001$

exibem curva de saturação de luz semelhante às plantas de sombra. $P$. gonoacantha é tipicamente uma espécie de sol (Carvalho 1994), porém suas plântulas são submetidas a condições de grande sombreamento dentro da mata e permanecem no banco de plântulas até a abertura de clareiras quando, então, crescem rapidamente.

A interação entre luz e inundação não foi expressiva no experimento realizado ao contrário dos resultados obtidos por Dale \& Causton (1992) com três espécies do gênero Veronica. A ausência de interação entre os dois fatores provavelmente está relacionada à saturação do aparato fotossintético das plântulas. Uma das exceções de interação foi a massa seca das folhas no fim do experimento. Esta foi mais drasticamente reduzida em plantas inundadas a pleno sol quando comparada às plantas inundadas sombreadas. É possível especular que esta resposta reflita um efeito sinergístico do estado de água e da luminosidade sobre eventos como abertura estomática e absorção de água (Björkman \& Powles 1984, Pezeshki et al. 1996).

Os sintomas de injúria mais evidentes foram observados nas raízes, onde a degeneração dessas reduziu a massa seca radicial. A decomposição de raízes está bastante relacionada com o aumento da atividade fúngica nos solos inundados, bem como à maior susceptibilidade das raízes aos microorganismos hospedeiros (Kozlowski 1997). 
Apesar da redução da massa seca radicial, não foram observadas diferenças no comprimento das raízes principais. É provável que isto se deva a um efeito de tamanho do vaso, pois as raízes apresentaram, frequentemente, comprimento maior que o recipiente utilizado.

Plântulas inundadas apresentaram, aos 60 dias, maior razão parte aérea/raiz. Esse resultado indica que o crescimento radicial foi mais drasticamente reduzido que o da parte aérea. De fato, esta resposta é esperada, pois as raízes são os órgãos mais diretamente afetados pela inundação, sendo tipicamente mais reduzidos que a parte aérea (Kozlowski 1997). A redução no crescimento da parte aérea das plântulas inundadas deve ter ocorrido principalmente devido à supressão da formação e expansão de folhas e internós, pois sintomas como necrose, senescência e abscisão foliares não foram expressivos. Considerando que a anoxie é a principal causa dos efeitos adversos da inundação (Kozlowski 1997), o crescimento reduzido das plântulas inundadas de $P$. gonoacantha, poderia ser explicado pelas seguintes hipóteses: a) baixa produção de ATP (Joly 1986, Vartapetian 1991); b) redução na produção e translocação de fotoassimilados para a respiração (Kozlowski 1997); c) decréscimo na taxa de assimilação de $\mathrm{CO}_{2}$ em razão do fechamento estomático (Tang \& Kozlowski 1982a, b; Pezeshki et al. 1996); d) redução na síntese e translocação de substâncias reguladoras do crescimento, como giberelinas e citocininas, do sistema radicial para a parte aérea (Reid \& Bradford 1984).
A produção de lenticelas hipertrofiadas pelas plântulas inundadas de $P$. gonoacantha poderia ser interpretada como adaptação para aumentar o transporte de $\mathrm{O}_{2}$ dos tecidos aéreos para as raízes, conforme demonstrado experimentalmente por Lobo \& Joly (1995) em plântulas de Talauma ovata. Embora o surgimento de lenticelas hipertrofiadas seja freqüente entre plantas inundadas (Lieberg \& Joly 1993, Joly 1991), estas nem sempre têm valor adaptativo podendo ser resultantes de mera alteração hormonal (Lobo \& Joly 1998).

Os resultados obtidos não esclarecem se a produção de lenticelas hipertrofiadas contribuiu para a sobrevivência das plântulas inundadas de $P$. gonoacantha, ou se essas estruturas resultaram apenas de alterações hormonais sem função adaptativa. Ensaios experimentais, como por exemplo o bloqueio dos orifícios das lenticelas (Lobo \& Joly 1995), poderiam elucidar essa questão.

O critério sugerido por Lobo \& Joly (1998) para classificar as espécies em tolerantes à inundação é a capacidade de manter ou aumentar a massa seca da parte aérea durante períodos de inundação similares aos seus habitats naturais. Conforme esse critério, plântulas de $P$. gonoacantha, com cinco meses de idade, mostraram-se pouco tolerantes à inundação, concordando com a sua ausência em sítios inundáveis das matas. Entretanto, aspectos ecológicos devem ser amplamente considerados para avaliar a possível colonização das espécies em áreas inundáveis (Scarano 1998) que depende da associação de diversos eventos como, por exemplo, dispersão e germinação (Scarano \& Crawford 1992).

Tabela 2. Valores médios das medidas de crescimento de Piptadenia gonoacantha que apresentaram interação significativa entre duas condições do solo (cc capacidade de campo e in inundado) e três níveis de luz (100\%, 70\% e 40\%). (MSF) massa seca das folhas e (PAPR) razão parte aérea/raiz. As médias do mesmo parâmetro seguidas da mesma letra não diferem entre si em $\mathrm{P}<0,05$.

\begin{tabular}{cccc}
\hline & & \multicolumn{2}{c}{ CONDIÇÃO DO SOLO } \\
\cline { 3 - 4 } MEDIDAS DE & & $\mathrm{cc}$ & in \\
CRESCIMENTO & NÍVEIS DE LUZ (\%) & & $0,23 \mathrm{a}$ \\
(TEMPO) & & $1,32 \mathrm{~d}$ & $0,66 \mathrm{~b}$ \\
MSF (60 dias) & 100 & $1,13 \mathrm{~cd}$ & $0,74 \mathrm{bc}$ \\
oo & 70 & $1,31 \mathrm{~d}$ & $2,24 \mathrm{a}$ \\
oo & 40 & $3,26 \mathrm{a}$ & $3,26 \mathrm{a}$ \\
PAPR (20 dias) & 100 & $2,42 \mathrm{a}$ & $3,52 \mathrm{a}$ \\
0 & 70 & $0,74 \mathrm{bc}$ & \\
\hline
\end{tabular}


Se por um lado, as sementes de $P$. gonoacantha têm pouca capacidade germinativa em condições inundadas, a dispersão na estação seca, a alta velocidade de germinação (Ferreira et al. 2000) e o rápido crescimento das plântulas são fatores que favoreceriam o seu estabelecimento antes das cheias. Como as plântulas de $P$. gonoacantha têm alto índice de sobrevivência à inundação, podem resistir ao estresse na estação chuvosa subsequente, sendo potencialmente uma espécie colonizadora de áreas com inundação sazonal.

Agradecimentos - Os autores agradecem ao CNPq e CAPES pela concessão de bolsa à primeira autora, aos funcionários da Embrapa Cerrados José Ferreira Paixão e Nelson de Oliveira Paes pelo auxílio no campo e às instituições financiadoras do projeto: PRONABIO, PROBIO, MMA, CNPq e BIRD-GEF.

\section{Referências bibliográficas}

BOARDMAN, N.K. 1977. Comparative photosynthesis of sun and shade plants. Plant Physiology 28:355-377.

BJÖRKMAN, O. \& POWLES, S.B. 1984. Inhibition of photosynthetic reactions under water stress: interaction with light level. Planta 161:490-504.

CARVALHO, P.E.R. 1994. Espécies florestais brasileiras: recomendações silviculturais, potencialidades e uso da madeira. EMBRAPA - CNPF, Brasília.

DALE, M.P. \& CAUSTON, D.R. 1992. The ecophysiology of Veronica chamaedrys, $V$. montana and $V$. officinalis. II. The interaction of irradiance and water regime. Journal of Ecology 80:493-504.

FERREIRA, J.N., RIBEIRO, J.F.R. \& GOMES, A.C. 2000. Germinação de sementes de Piptadenia gonoacantha Mart. sob inundação. Boletim do Herbário Ezechias Paulo Heringer 5:95-104.

HARMS, W.R., SCHREUDER, H.T., HOOK, D.D., BROWN, C.L.\& SHROPSHIRE, F.R. 1980. The effects of flooding on the swamp forest in Lake Ocklawaha, Florida. Ecology 61:1412-1421.

JOLY, C.A. 1986. Heterogeneidade ambiental e diversidade de estratégias adaptativas de espécies arbóreas de Mata de Galeria. Anais do X Simpósio Anual da Academia de Ciências de São Paulo. Perspectivas de Ecologia Teórica, p.19-38.

JOLY, C.A. 1991. Flooding tolerance in tropical trees. In Plant life under oxygen deprivation: ecology, physiology and biochemistry. (M.B. Jackson, D.D. Davies \& H. Lambers, ed.). Academic Publishing, The Hague, p.23-34.

KOZLOWSKI, T.T. 1997. Responses of woody plants to floodingand salinity. Tree Physiology Monograph $\mathrm{N}^{\circ} 1$. Heron Publishing, Victoria, Canada. On line http:// heronpublishing.com/tp/monograph/kozlowski.pdf: 1-29.
LIEBERG, S.A. \& Joly, C.A. 1993. Inga affinis DC (Mimosaceae): germinação e tolerância de plântulas à submersão. Revista Brasileira de Botânica 16:175-179.

LOBO, P.C. \& Joly, C.A. 1995. Mecanismos de tolerância à inundação de plantas de Talauma ovata St. Hil. (Magnoliaceae), uma espécie típica de matas de brejo. Revista Brasileira de Botânica 18:177-183.

LOBO, P.C. \& Joly, C.A. 1998. Tolerance to hypoxia and anoxia in neotropical tree species. In Ecophysiological strategies of xerophytic and amphibious plants in the neotropics. (F.R. Scarano \& A.C. Franco, eds.).Series O ecologia Brasiliensis, PPGE-UFRJ, Rio de Janeiro, v. IV p.137-156.

MARQUES, M.C.M. \& JOLY, C.A. 2000. Germinação e crescimento de Calophyllum brasiliense (Clusiaceae), uma espécie típica de florestas inundadas. Acta Botânica Brasileira 14(1):113-120.

PEZESHKi, S.R., PARDUE, J.H. \& DELAUNE, R.D. 1996. Leaf gas exchange and growth of flood-tolerant and floodsensitive tree species under low soil redox conditions. Tree Physiology 16:453-458.

PONNAMPERUMA, F.N. 1984. Effects of flooding on soils. In Flooding and plant growth. (T.T. Kozlowski, ed.). Academic Press, San Diego, p.10-45.

REID, D.M. \& BRADFORD, K.J. 1984. Effects of flooding on hormone relations. In Flooding and plant growth. (T.T. Kozlowski, ed.). Academic Press, San Diego, p.195-219.

RIBEIRO, J.F. \& WALTER, B.M.T. 1998. Fitofisionomias do Bioma Cerrado. In Cerrado: ambiente e flora (S.M. SANO \& S.P. Almeida, eds.). EMBRAPA Cerrados, Brasília, p.87-166.

SCARANO, F.R. \& CRAWFORD, R.M.M. 1992. Ontogeny and the concept of anoxia-tolerance: the case of the Amazonian leguminous tree Parkia pendula. Journal of Tropical Ecology 8:349-352.

SCARANO, F.R. 1998. A comparison of dispersal, germination and establishment of woody plants subjected to distinct flooding regimes in brazilian flooding-prone forests and estuarine vegetation. In Ecophysiological strategies of xerophytic and amphibious plants in the neotropics. (F.R. Scarano \& A.C. Franco, eds.). Series Oecologia Brasiliensis, PPGE-UFRJ, Rio de Janeiro, v. IV, p.177-193.

TANG, Z.C. \& KOZLOWSKI, T.T. 1982a. Physiological, morphological, and growth responses of Platanus occidentalis seedlings to flooding. Plant Soil 66:243-255.

TANG, Z.C. \& KOZLOWSKI, T.T. 1982b. Some physiological and growth responses of Betula papyrifera seedlings to flooding. Physiology Planttarum 55:415-420.

VARTAPETIAN, B.B. 1991. Flood-sensitive plants under primary andsecondary anoxia: ultrastructural and metabolic responses. In Plant life under oxygen deprivation. (M.B. Jackson, D.D. Davies \& H. Lambers, ed.). SBP Academic Publishing, The Hague, p.201- 216. 